\title{
GRAFITE E PIXAÇÃO:1 INSTITUCIONALIZAÇÃO E TRANSGRESSÃO NA CENA CONTEMPORÂNEA
}

Luizan Pinheiro da Costa

\author{
I like the druggy downtown kids \\ who spray paint walls and trains \\ I like their lack of training \\ their primitive technique. ${ }^{2}$ \\ Trouble With Classicists \\ Lou Reed \& John Cale \\ Songs For Drella
}

\section{1. dos termos}

Comecemos com uma distinção trivial entre o grafite e a pixação segundo o uso dos termos que se faz para designar os dois tipos de expressão. Uma posição necessária para dimensionar tais práticas na história da arte, sem pretendermos a palavra definitiva, visto que ela sempre há de nos faltar. Mesmo assim cabe-nos indicar a estrada que vimos trilhando na companhia deste objeto sujo que nos fascina. O primeiro momento se deu em 2002 com o ensaio Pichação: Informalismo Urbano, monografia para uma disciplina no Mestrado da EBA/UFRJ, que o publicamos em seguida como Pichação: Expressionismo Abstrato e Caos Urbano em 2005 na Revista Internacional de Folkcomunicação (on line). No final de 2006 fizemos a comunicação Pixação: Excitação das Zonas no Encontro da Pós-Graduação da EBA/UFRJ, uma espécie de ensaio para a tese que se anuncia, caracterizando nossa abordagem estética dessa prática: o uso do termo pixação com " $\mathrm{x}$ " dá a dimensão do que apontamos na abordagem. E cá estamos nós diante de mais um acontecimento da arte, e este trabalho se ergue como mais um muro a ser desvirginado em noite periférica.

\footnotetext{
${ }^{1}$ Os pichadores costumam grafar o termo pichação com x (pixação) o que é mais usual na fala dos grupos, gangs ou galeras. Assim como pixo para uma determinada pichação sobre qualquer superfície, o equivalente de uma pintura, desenho ou gravura, isto é, o objeto em si. Foi dessa forma que se grafou no título do livro Tsss: a grande arte da pixação em são paulo, brasil, BOLETA. (Org.). São Paulo: Editora do Bispo, 2005. E por coerência poético-política assim o utilizamos no trabalho; pixação, pixador, pixar, pixo.

2 "Eu gosto dos garotos drogados do centro da cidade, que pintam com spray as paredes e os trens. Eu gosto de sua falta de treino e de sua técnica primitiva".
} 
Do que vimos geralmente nos mais diversos autores é a utilização do termo graffiti ${ }^{3}$ plural do termo italiano - grafitto (rabisco), para designar os tipos de intervenções parietais surgidas desde a Pré-História, passando por Pompéia, o Maio de 68, ${ }^{4}$ as intervenções em Nova York na década de 60/ 70 até os atuais grafites artísticos urbanos desenvolvidos desde os disparos novayorkinos.

O professor português Jorge Bacelar afirma que:

“Actualmente pode-se tentar categorizar as suas várias manifestações, desde o graffiti dos gangs, com a finalidade de demarcar territórios, o graffiti daqueles que utilizam as paredes como veículo das suas opiniões e mensagens, sejam políticas, sexuais, humorísticas (ou mesmo como exibição de total ausência de idéias...) e por fim uma última modalidade que emergiu e se consolidou nos últimos 30 anos, que se poderá, à falta de melhor designação, chamar 'graffiti artístico"'. 5

Assim, na maioria dos casos usa-se o termo italiano graffiti, mesmo no português de Portugal, como demonstra o professor Jorge Bacelar, por ser abrangente e alojar as diversas práticas de intervenção. É o diferencial deste termo, pois se tornou uma espécie de termo genérico para todo e qualquer tipo de inscrição e rabisco feito com qualquer material sobre qualquer suporte: muro, parede, teto etc., incluindo também os grafites artísticos urbanos.

No Brasil, o termo grafite 6 , em português, refere-se aos grafites artísticos que se desenvolveram aqui a partir do graffiti americano no início da década de 80, não à toa mantém os estrangeirismos para designar seus diversos estilos: wild stile, bomb, throw up, stencyl art etc. Usa-se também o termo grafito tal como Gustavo Barbosa usou em seu livro Grafitos de Banheiro: A Literatura Proibida para outros tipos de inscrições e incisões com materiais diversos tais como giz, caneta, caco de telha ou outros materiais

3 "A palavra "graffiti" é derivada da palavra latina "graphium," que significa "escrever." Foi usada originalmente por arqueólogos descrever os desenhos e as escritas encontrados em edifícios e em monumentos antigos em Pompéia, Egito e nas catacumbas romanas. A definição mais básica do termo "graffiti" é "inscrições ou os desenhos rabiscados, riscados, ou pulverizados em uma superfície, originalmente como inscrito em paredes antigas." In: www.geocities.com/laeeque1650/graffiti.html

${ }^{4}$ O professor Voltaire Schilling diz sobre esse período: "Assemelhou-se aquele ano aloucado a um caleidoscópio, para qualquer lado que se girasse novas formas e novas expressões vinham à luz. Foi uma espécie de fissão nuclear espontânea que abalou as instituições e regimes. Uma revolução que não se socorreu de tiros e bombas, mas da pichação, (grifo nosso) das pedradas, das reuniões de massa, do alto-falante e de muita irreverência. Tudo o que parecia sólido desmanchou-se no ar".

5 BACELAR, Jorge. Notas sobre a arte mais velha do mundo. In: http:// bocc.ubi.pt

- BAUDRILLARD, Jean. "Kool Killer on A Insurreição Pelos Signos." Revista Cine Olho no 5/6 jun/jul/ago 1979. p. 36. Pode ser encontrado também no site: riz̧oma.net. 
pontiagudos sobre suportes e lugares diversos. E pixação (com " $x$ " ou "ch") é o termo usado especificamente no Brasil para designar as intervenções e inscrições que usa o spray mas se difere do grafite na forma, não obstante originados dos $\operatorname{tags}^{7}$. Essa distinção ficou mais nítida na medida em que o sistema de arte passou a considerar o grafite como arte.

Já a pixação é originária do piche, que é o resíduo da destilação de diversos alcatrões, especialmente da hulha. É obtido do petróleo e é usado na pavimentação de ruas e estradas. ${ }^{8}$ Foi muito usado para escrever em muros e paredes no período da ditadura militar. Com o surgimento das latas de tinta spray (color jet), o piche saiu de cena mas a pixação não. E assim passou-se a chamar de pixação às intervenções feitas também com spray como ocorre atualmente. Cabe observar que o spray criou o elo de ligação entre o grafite e a pixação nas últimas quatro décadas, tanto por questões formais quanto técnicas, a ponto de em alguns casos se (con)fundirem.

\section{2. dos disparos}

No final dos anos 60 e início dos 70 o termo graffiti foi usado pelo jornal americano New York Time para designar a intervenção de TAKI 138 que invadiu a cidade de Nova York; logo o termo passou a ser adotado por diversos autores. ${ }^{9}$ Mas os tags de JULIO 204 já havia tomado Nova York de assalto. ${ }^{10}$ Assim, as intervenções nos muros e trens de metrô de Nova York foram o ponto inicial de uma série de intervenções poético-políticas a assinalar uma outra visualidade contemporânea. Um modo de experimentar a cidade confrontando as relações sócio-econômicas das minorias nos guetos, mas que se davam a partir da investida sígnica nos espaços configurados da metrópole. Baudrillard em seu clássico Kool Killer on $A$ Insurreição Pelos Signos nos dá a dimensão da potência intervencionista daquela época. Ele diz: "Uma coisa é certa: tanto muros pintados como graffitis, nasceram após a repressão das grandes revoltas urbanas de 66/70. Trata-se de uma

\footnotetext{
7 Espécie de assinatura de onde se originou o grafite urbano. Era acompanhado por um número, como por exemplo, os primeiros a surgirem em Nova York: JULIO 204 e TAKI 138.

8 In: Dicionário Quimicamente Falando do $\mathrm{Pro}^{\circ}$ Rossetti: www.rossetti.eti.br.

9 Cf. BACELAR, Jorge. Notas sobre a arte mais velha do mundo. In: http://bocc.ubi.pt GILLER, Sarah. Graffiti: Inscribing Transgression on the Urban Landscape. In: www.artcrimes.com/index/talk.html

${ }^{10}$ Cf. TUCKER, Daniel. Graffiti: art and crime. In: http://www.artcrimes.com/index/talk.html
} 
ofensiva tão "selvagem" quanto as revoltas, mas de um outro tipo, uma ofensiva que mudou de conteúdo e de terreno. Estamos face a um novo tipo de intervenção na cidade" Intervenção portanto que insurgiu como uma prática de luta, uma invasão sígnica e territorial, uma fala em que comportava um poder mobilizador como gesto e expressão de minorias guetificadas. E Baudrillard ampliava a idéia de gueto: "cada espaço/tempo da vida urbana é um gueto e todos eles estão conectados entre si (...) todos estão alinhados no seu delírio respectivo de identificação com modelos de simulação orquestrados". Eis que a linha de fuga sígnica se dá por essa afirmação intervencionista, guerrilheira em que a lata de spray tornouse uma arma.

Mas um diferencial emerge quando o olhar recai sobre as manifestações do grafite na cena contemporânea dos dias de hoje. Ao nascerem em Nova York naqueles anos, a dimensão intervencionista e política caracterizava a forte presença do grafite colocando em xeque as questões de classe, raciais e estéticas. Nesta primeira década do terceiro milênio, vimos a absorção, diluição e domesticação dessa expressão urbana pelo sistemas de arte. Daquilo que Baudrillard indicava na década de 70: "mil jovens armados com pincéis e sprays para embaralhar a sinalética urbana, desfazer a ordem dos signos" e que apontava para um modelo de resistência à ordem artística burguesa agenciada nas grandes metrópoles do capital, virou moda, modismo mumificado.

\section{3. grafite: da perda}

Arte de intervenção domesticada pelas estratégias de absorção, o grafite perde dia a dia o trem da história para o cinismo extático da mercadoria, do holofote, ganhou status de arte de galeria com direito à curadoria, patrocínio e apoio governamental como no caso da recente exposição Fabulosas Desordens no espaço da Caixa Cultural no Rio de Janeiro em março último. Agenciado por arquitetos, curadores e produtores culturais que o integram ao modelo visual contemporâneo numa estética que embevece e satisfaz: harmonia e justa-proporção imemorial reeditada por exímios grafiteiros. Num caso bem específico, o do Rio de Janeiro, foi abocanhado pela classe média da zona sul carioca que o levou como arte decorativa para as paredes de seus apartamentos para diminuir o tédio de crianças enjauladas na assustadora metrópole em decomposição. Um drops

${ }^{11}$ BAUDRILLARD, Jean. Op. Cit. p. 39. 
estético para o longe das balas perdidas. Logo se vê que o grafite entrou na moda. Tá na roupa, no carro, no tênis, na mídia-mundo. O grafite, enfim, foi se transformando em arte de galeria ${ }^{12}$, perdendo a potência política e intervencionista que privilegiava a cidade como seu espaço de intervenção e discurso, colocando-o como resistência a um modelo de arte completamente sujeito aos mecanismos de controle de museus, galerias, bienais, publicidade. Ordem na cidade. Harmonia e beleza no desejo asséptico contemporâneo. Com isso vê-se que o grafite, nascido dos conflitos raciais, da miséria econômica e cultural como um disparo na direção da ordem burguesa de homogeneização dos sujeito nas metrópoles modernas, reinstala-se como o decorativismo morno em nome do novo nas mãos de atravessadores da arte, ávidos pela descoberta de talentos que venham azeitar as engrenagens do velho sistema de arte.

\section{4. pixação: da explosão}

O risco corta o concreto e tudo o que se quer como ordem perde-se na contaminação dos traços. Linhas desordenadas sobrepondo-se em explosão. Tags acelerados no incomensurável do espaço. A cidade, esse grande acelerador de partículas a reinvestir os signos dessa dimensão artístico-estética ad infinitum. Paredes de cidades como palco da efemeridade de cada traço-gesto que escapa a uma conjunção uniforme. Sordidez em cada olhar. Riscos a possuir o espectador, ativando seu gozo torpe para logo voltar ao seu letárgico desespero urbano. As cidades contemporâneas vestem-se desde muito com uma roupagem cáustica. Um fechar dos olhos machucados pela desinstalação da assepsia citadina assombra as sombras assustadas no cotidiano vazio. Tramas incisivas que instauram um outro cenário para a-trair os olhos numa tentativa de decodificação dos signos em explosão. Mas os signos não são decodificáveis, identificáveis. A identificação é o que submete o signo à sua condição asfixiante. Sua redutora redenção. Os pixos são tão somente matérias espúrias com sua

\footnotetext{
${ }^{12} \mathrm{O}$ surgimento das galerias especializadas em grafite no Brasil como a Grafiteria e a Choque Cultural em São Paulo e Galeria Adesivo em Porto Alegre. Grandes exposições como a Graffiti no Brooklyn Museum de Nova York: In: O Globo. 09/07/06. Segundo Caderno. p. 8. Na matéria de capa Sociedade do Grafite na Revista Ocas. N. 42. Fev. 2006. E a mais recente exposição FABULOSAS DESORDENS na Galeria da Caixa Cultural no centro do Rio de Janeiro em março último. Acirraou o debatesobre a institucionalização do grafite. uma sobre a Cf. Graffiti Brasil livro de Tristan Manco junto com os brasileiros Lost Art e Caleb Neelon que mostram a produção do grafite brasileiro.
} 
nadificação perfeita. Expurgadas por si, num si sem sim. Pois que é negação de si e daquilo que é pensável sustentar dos signos. Eis aqui a fala já em si distorcida porque fala do que não existe mais. Ou do que ainda virá como apagamento, mutabilidade, efemeridade.

\section{5. pixação: o outro lugar}

Intervenção radical impondo à matéria uma desnorteante visualidade. Cidade-suporte versus artista-pixador, pixador-artista, nenhum dos dois e ambos ao mesmo tempo. Nenhum espaço limítrofe às interferências. Todo espaço possível. Intumescido. Gordo. Engordado pelos olhos do dono? Não. A cidade não tem dono. É campo ampliado, expandido à exaustão. Todo o espaço é público. Publicável. Apto à recepção de todo tipo de signo que o expõe. O espaço é todo convulsão a abrigar as potências intervencionistas de naturezas díspares. O que revela que por contaminação a pixação está no nível mais abismal dos instintos criativos. Nada limita sua explosão instintiva. Nem a lei, nem a ordem, nem a repressão. Eis porque a cada dia os espaços são tomados por esses signos insólitos. Nada alimenta mais a deflagração da pixação do que as energias dilacerantes que emergem das profundezas do corpo do artista-pixador compondo uma trama que impregna os diversos espaços da cidade: Londres, Fortaleza, Belém, Rio, São Paulo, Paris, Berlim, Bombaim e o que há por vir a ser vil. A pixação invadiu os espaços. Globalizou a ordem do dia como no seu momento inicial: hálitos cortantes da bocas das cidades entontecidas. Extrema condição de possibilidades de seu ser arte. E um grande $\mathrm{N} \tilde{\mathrm{A}} \mathrm{O}$ aos controladores de vôos da imaginação e criação com escalas no solo pátrio. A possibilidade artística e espúria como o outro lugar de alteração de uma homogeneidade estética absolutizada em discursos legais. Pixação: arte contemporânea. Não aquela. Esta que está aí por toda parte em todas as cidades. Sem rosto. Sem dentes. Sem holofotes. Vão e vejam. 


\section{Bibliografia}

BACELAR, Jorge. Notas sobre a arte mais velha do mundo. In: http://bocc.ubi.pt

BAUDRILLARD, Jean. “Kool Killer ou A Insurreição Pelos Signos.” Revista Cine Olho no 5/6 jun/jul/ago 1979. p. 36. Pode ser encontrado também no site: rizoma.net.

BOLETA. (Org.). Tsss: a grande arte da pixação em são paulo, brasil, São Paulo: Editora do Bispo, 2005.

GILLER, Sarah. Graffiti: Inscribing Transgression on the Urban Landscape. In: www.artcrimes.com/index/talk.html

TUCKER, Daniel. Graffiti: art and crime. In: www.artcrimes.com/index/talk.html 